\title{
EXPLORE
}

\section{Cobit 5 dalam Proses Audit Tata kelola Teknologi Informasi pada Dinas Pendidikan Kabupaten Tulang Bawang - Lampung}

\author{
Iwan Purwanto, Rully Mardjono \\ Prodi Sistem Informasi \\ Jurusan Teknik Informatika, Fakultas Teknologi Industri \\ Universitas Trisakti \\ Jakarta, Indonesia \\ iwan.purwanto@trisakti.ac.id., rully.mardjono@trisakti.ac.id
}

\begin{abstract}
Abstrak- Peran Teknologi informasi dan komunikais dewasa ini tidak dapat terelakkan lagi. Seala lini dengan berbagai sub domain membutuhkan peran sertanya dalam proses penunjang kegiatan operasional, baik sebagai main core atau pun support. Organisasi yang bergerak dalam bisang pelayanan maupun manufacturing secara sinergi dan berkesinambungan membutuhkan peran serta implementasi teknologi sebagai pendorong proses bisnisnya. Tidak saja hanya pada instansi swasta, dewasa ini instansi pemerintah pun di gadang-gadang untuk dapat ikut andail dalam perkembangan teknologi dan komunikasi. Oleh karena itu organisasi perlu menyelaraskan strategi organisasi dengan strategi TI guna mencapai tujuan organisasi. Namun di lapangan terkadang sulit sekali menyeleraskan antara kebutuhan organisasi dengan kebutuhan TI. Diperlukan pendekatan yang tepat dan komperhensif seta kemudahan bagi suatu organisasi dalam rangka menyelaraskan antara strategi organisasi dengan kondisi TI pada organisasi tersebut. Cobit 5 memberikan pointer yang cukup dalam mendesain kebutuhan organisasi untuk memenuhi kebuutuhan IT organisasinya. Sebagai panduan pengembangan insfrastruktur dan penentuan nilai guna IT dalam organisasi COBIT 5 juga memberikan kemudahan dalam penentuan tikngat kebergunaan teknologi terbarukan. Dinas Pendidikan merupakan pelaksana unsur kepemerintahan pada bidang Pendidikan baik Pendidikan formal maupun non formal. Meninjau tingkat akurasi data yang begitu penting bagi pemerintah daerah dan pusat, maka implementasi TI dangat dibutuhkan dalam proses percepatan penghimpunan datanya. Guna meningkatkan peran serta percepatan dan akurasi data pada dinas Pendidikan COBIT 5 menyajikan bebrapa standar dalam pengolahannya, yaitu: EDM (Evaluate, Direct, dan Monitoring), DSS (Delifery, service, dan Support), Serta APO (Align, Plan, dan Organize). Kompopnen tersebun peneliti anggap penting guna mengukur tingkat kematangan organisasi, Hasil yang diharapkan dari kajian evaluasi adalah gambaran kondisi tata kelola TI berjalan dan rekomendasi guna perbaikan organisasi dengan menggunakan perhitungan tingkat kematangan (maturity level) melalui tanya jawab dan penghimpunan data (kuisioner) yang berhubungan dengan penentuan pada tingkat mana kondisi teknologi informasi telah di implementasikan pada Dinas Pendidikan Kabupaten Tulang Bawang, Provinsi Lampung.
\end{abstract}

Kata Kunci: Tatakelola TI, Cobit 5, EDM, DSS, APO, Dinas Pendidikan

\section{Pendahuluan}

Informasi merupakan sumber utama bagi suatu enterprise. Teknologi menjadi jembatan bagi penyampaian informasi kepada sakeholder sebagai pemangku kepentingan informasi. Dalam melakukan peninjauan tingkat mauruty TI dalam suatu organisasi bayak beberapa resource yang linier dalam proses penentuan nilai kematangan IT dalam suatu organisasi. Saat ini, solusi implementasi resmi ISACA mengikuti proses yang berurutan, memunculkan beberapa masalah terkait dengan kurangnya komitmen dari manajemen puncak dan solusi yang tidak selaras. COBIT 5 adalah kerangka kerja yang banyak digunakan untuk menerapkan tata kelola perusahaan IT (GEIT) yang baik [1]. Pengukuran tingkat kapabilitas didasarkan pada COBIT

5.0 untuk keamanan Informasi dan Pedoman ISO 27001:2013 sebagai nilai terhadap peringkat komponen Tata Kelola Keamanan Informasi [2][5]. Tatakelola teknologi pada pengola data merupakan asset penting bagi suatu institusi ataupun organisasi. Kurang baiknya pengolahan data berdasarkan tata kelola Teknologi Informasi mampu menimbulkan suatu permasalahan yang pada akhirnya mampu memberikan suatu kelemahan suatu organisasi, sehingga melalui kelemahan tersebut akan menumbulkan suatu ancama (threats) [7]. Berbagai macam dampak dari ancaman diantaranya adalah kehilangan data, kebocoran informasi yang bersifat penting, biasnya tingkatan suatu data, akan menimbulkan polemic tersendiri bagi organisasi. Tata kelola TI yang

\section{Vol.12 no.2|Desember 2021}

EXPLORE : ISSN: 2087-2062, Online ISSN: 2686-181X / DOI: http://dx.doi.org/10.36448/jsit.v12i2.2361 
baik dapat membantu mendukung keberhasilan organisasi dalam mencapai tujuannya. Untuk mengetahui sejauh mana tata kelola TI diterapkan, tata kelola TI perlu diaudit salah satunya dengan Cobit 5 [4]. Dinas Pendidikan pada hakikatnya memiliki tugas dan tanggung jawab dalam merencanakan, melaksanakan, mengawasi, mengevaluasi, dan membuat pertanggung jawaban tentang pelaksanaan tugad pada bidnag Pendidikan di lingkungannya. Saat ini, penerapan manajemen TI di Dunia Pendidikan terutama yang berorientasi pada instansi kepemerintahan telah menjadi bagian integral dari manajemen institusi dan semua fungsi bisnis, mulai dari proses belajar mengajar, sistem informasi akademik, sistem administrasi \& pembayaran, pendaftaran penerimaan mahasiswa dan sebagainya. Penanganan incident response merupakan kegiatan pengelolaan dan evaluasi TI yang harus dilakukan oleh segala lini Pendidikan di Indonesia [16].

\section{Metodologi}

Penelitian ini menggunakan data kualitatif berupa wawancara serta penghimpunan literatur terkait. Pada sisi lain penelitian ini juga menggunakan data kuantitatif melalui penyebaran kuisioner. Alur penelitian ini dapat di lihat pada gambar 1 di bawah ini yang terdiri dari 7 (tujuh) alur, yaitu:

1. Tinjauan pustaka yang dilakukan dengan melakukan peninjauan terhadap literatur yang terdiri dari dokumen serta informasi yang berkaitan dengan subjek penelitian.
2. Penelitian ini lebih melakukan pendekatan pada 3 (tiga) sub domain, yaitu;

a. EDM (Evaluate, Direct, dan Monitoring),

b. DSS (Delivery, service, dan Support),

c. Serta APO (Align, plan, dan Organize).

3. Proses pengidentifikasian dokumen dilakukan dengan menggunakan metode RACI (Responsibility, Accountability, consulted, informed) dimana peneliti menentukan delapan responden yang memiliki peranan dan tanggung jawab dalam pengambilan keputusan yang kemudian dipetakkan dalam Cobit 5.

4. Metode pengumpulan data yang dilakukan dengan meggunakan penyebaran kuisioner, yang dilanjutkan dengan melakukan wawancara, guna memperjelas pengisian data kuisioner serta menghimpun data laind alam bentuk dokumen untuk dilakukan proses lebih lanjut.

5. Pengolahan data yang dilakukan dengan mengan menggunakan data kuisioner dan pengolahan data kuantitatif, hingga perlu dilakukan penyederhanaan dan penyajian yang lebih sistematis.

6. Proses penganalisaan data dengan menggunakan Teknik Deskriftif Aritmatika guna melakukan penggambaran variable penelitian dalam proses pengukuran.

7. Tahap terakhir adalah tahap penarikan kesimpulan berdasarkan penghuimpunan dan pengolahan data di atas.

Secara rinci aktifitas penelitian dapat digambarkan pada gambar 1 di bawah ini:

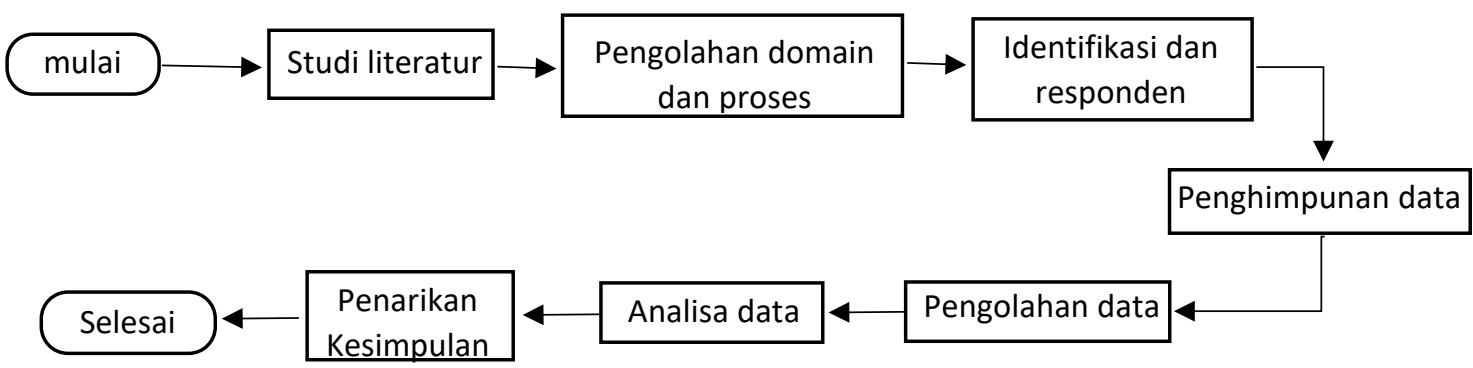

Gambar 1. Metodologi penelitian

\section{Hasil dan Pembahasan}

\section{A. Cobit 5}

Berdasarkan 5 domain yang terdapat dalam Cobit 5 terdapat 37 proses yang lebih berorientasi pada proses siklus hidup yang bermuara pada aktifitas tata kelola TI. Akyifitas tersebut merupakan penggambaran domain yang lebih berorientasi pada pemecahan suatu masalah. Tahapan yang dieksekusi dalam domain adalah domai EDM (Evaluate, Direct, dan Monitoring), DEM 03.
Memastikan pengiriman benefits, EDM04. Memastika pengoptimalan sumber daya, APO02. Tata Kelola Strayegi, APO04. Mengelola Inovasi. APO07. Mengelola Sumber Daya Manusia. APO11. Tata Kelola Kualitas., APO12. Mengelola Persetujuan dan Layanan Proses., APO13. Tata Kelola Keamanan., ME01. Memantau mengevaluasi, Menilai kinerja dan kesesuaian. 
Tabel 1 Hasil penentuan pemetaan tujuan perusahaan

\begin{tabular}{|c|c|c|c|}
\hline \multicolumn{4}{|c|}{ Tujuan Organisasi dipetakkan ke dalam tujuan Governance } \\
\hline \multirow{2}{*}{\multicolumn{2}{|c|}{ BSC Dimension }} & \multicolumn{2}{|c|}{$\begin{array}{c}\text { Relational to Governance } \\
\text { Objective }\end{array}$} \\
\hline & & $\begin{array}{c}\text { Benefits } \\
\text { Realization }\end{array}$ & $\begin{array}{c}\text { Risk } \\
\text { Optimation }\end{array}$ \\
\hline \multirow[t]{5}{*}{ Costumer } & 6. Customer-oriented services culture & $P$ & \\
\hline & 7. Business Service Continuity and availability & & $P$ \\
\hline & 8. Agile response to a changing business environment & $P$ & \\
\hline & 9. Information based - Strategic decision making & $P$ & $P$ \\
\hline & 10. Opination service delivery cost & $P$ & \\
\hline \multirow[t]{4}{*}{ Internal } & 11. Optimization of business process functionality & $P$ & \\
\hline & 12. Optimization of business process cost & $P$ & \\
\hline & 13. Managed business change programs & $P$ & $P$ \\
\hline & 14. Operational staff productivity & $P$ & \\
\hline \multirow{2}{*}{$\begin{array}{l}\text { Learned and } \\
\text { growth }\end{array}$} & 16. Skill and motivated people & & $P$ \\
\hline & 17. Product and business innovation culture & $P$ & \\
\hline
\end{tabular}

\section{B. Pembahasan}

Metode Cobit 5 memiliki 5 domain dan 37 proses, sementara dalam penelitian ini peneliti hanya mengambil domain kedekatan berdasarkan IT-Related Goal to process. Berdasarkan kedekatan tersebut, dapat pemetaan berdasarkan kebutuhan domain yang digambarkan pada table 2 di bawah ini. Domain yang berindikasikan $P$ yang merupakan penggambaran dari dara primer memiliki keterkaitan dengan aktifitas yang berhubungan erat kea rah IT Investment

Tabel 2 Pemetaan kebutuhan domain

Pemetaan Cobit 5 mengarah pada hubungan IT ke aktifitas

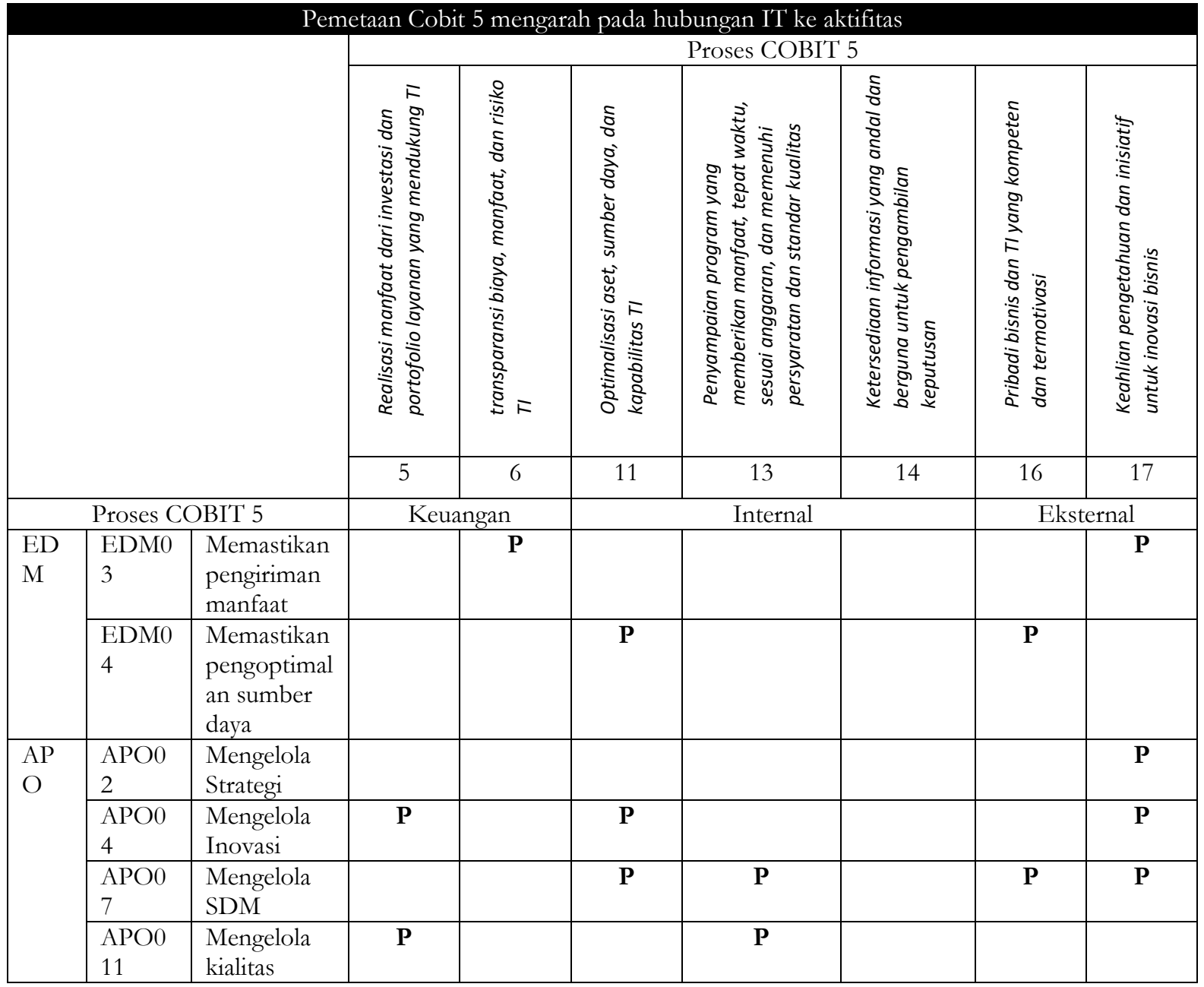

Vol.12 no.2|Desember 2021

EXPLORE : ISSN: 2087-2062, Online ISSN: 2686-181X / DOI: http://dx.doi.org/10.36448/jsit.v12i2.2361 


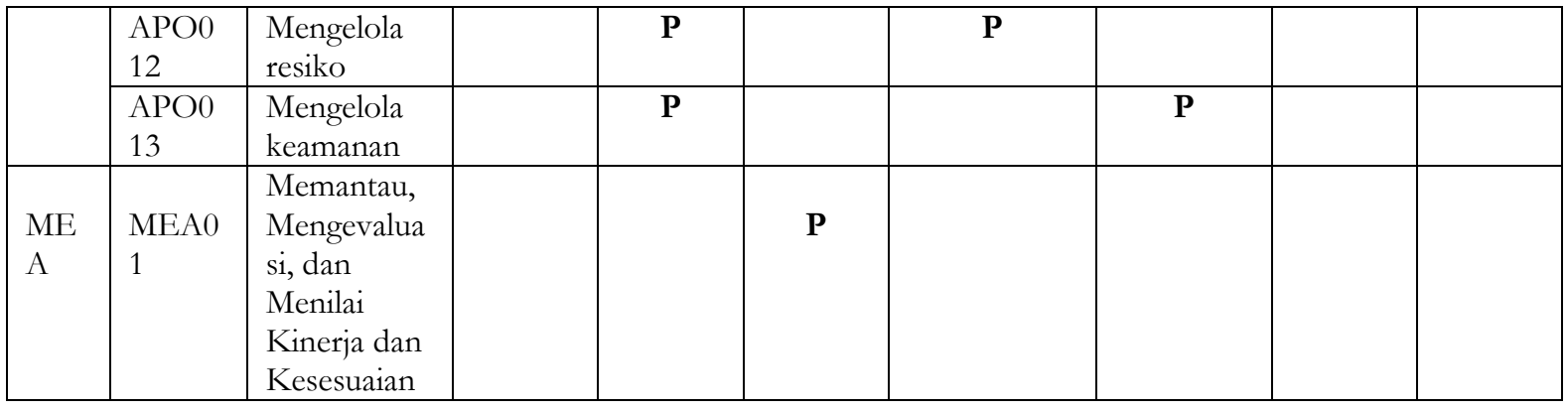

\section{Pengumpulan data}

Penghimpunan data dilakukan dengan menggunakan proses wawancara, observasi, dan penyebaran kuisioner. Proses wawancara dilakukan dengan mengajukan beberapa pertanyaan kepada pemangki kepentingan yang berada dalam ranah 'primer'.

Tahap observasi dilakukan dengan cara melakukan pengamatan secara langsung proses berjalan pada Dinas Pendidikan Kabupaten Tulang Bawang. Berdasarkan hasil pengamatan akan dilakukan verifikasi terhadap sub sistem terkait pada Dinas Pendidikan Kabupaten Tulang Bawang.

Tahap berikutnya adalah penyebaran kuisioner, dalam tahap ini pertanyaan dibuat secara tertulis dengan interval jawaban dalam sekala 0-5. Kuisioner ditujukan kepada responden yang memiliki kepentingan terhadap penggunaan sistem dan teknologi di lingkungan Dinas Pendidikan Kabupaten Tulang Bawang-Lampung.

\section{Pengujian}

Tahap pengujian dilakukan dengan menggunakan perangkat lunak audit sistem. Software yang digunakan dalam aktifitas pengujian ini adalah ACL (Audit
Command Language) yang merupakan satuan dalam software GAS (Generalized Audit Software), dimana GAS merupakan suatu tipe software audit utama. Software ACL merupakan interactive action yang menghubungkan pengguna dengan komputer. ACL membantu auditor dalam menghasilkan data clien melalui beberapa fungsi, diantaranya adalah: attribute sampling, record aging, histogram generation, duplicate checking, file printing, dan file comparation.

\section{E. Analisa Data}

Dalam tahap ini, peneliti akan melakukan Analisa terhadap suatu data dberdasarkan aktifitas uji validasi, dimana aktifitas ini akan menghasilkan tingkat kematangan (maturity level) suatu sistem berdasarkan hasil petik data yang dilakukan sebelumnya yaitu kuisioner yang telah dilakukan pengujian secara validitas dan reabilitas. Setalah hal tersebut dilakukan akan dilakukan kegiatan Analisa yang akan dilajutkan dengan tahap rekomendasi. Tingkat kematangan (maturity level) pada aktivitas ini dibagi dalam 6 level, seperti yang tertera pada table 3 di bawah ini.

Tabel 3 Skala tingkat kematangan (Maturity level)

\begin{tabular}{|c|c|}
\hline $\begin{array}{c}\text { Indeks } \\
\text { kematangan }\end{array}$ & Tingkat Kematangan \\
\hline $0-0,49$ & 0 - Non Existent \\
\hline $0,5-1,49$ & 1 - Initial/Ad hoc \\
\hline $1,5-2,49$ & 2 - Reputable but intuitive \\
\hline $2,5-3,49$ & 3 - Define process \\
\hline $3,5-4,49$ & 4 - Manage and Measurable \\
\hline $4,5-5,0$ & 5 - Optimized \\
\hline
\end{tabular}

Berdasarkan hasil kuisioner evaluasi tingkat kematangan tatakelola sistem dan TI pada Dinas Pendidikan Kabupaten Tulang Bawang-Lampung berdasarkan 58 responden menunjukan bahwa hasil indeks kematangan pada tiap domain proses yang telah ditentukan dapat dilihat pada table 4 di bawah ini.

Tabel 4 Domain hasil instrument

\begin{tabular}{lcl}
\hline \multicolumn{1}{c}{ Domain dan Proses } & $\begin{array}{c}\text { Current } \\
\text { Maturity }\end{array}$ & Kondisi \\
\hline EDM03 - Memastikan pengiriman manfaat & 4,45 & Optimized \\
\hline EDM04 - Memastikan pengoptimalan sumber daya & 3,91 & Manage and Measurable \\
\hline APO02 - Mengelola Strategi & 3,65 & Manage and Measurable \\
\hline APO04 - Mengelola Inovasi & 3,65 & Manage and Measurable \\
\hline APO07 - Mengelola SDM & 4,12 & Manage and Measurable \\
\hline APO011 - Mengelola kialitas & 4,10 & Manage and Measurable \\
\hline
\end{tabular}

Vol.12 no.2|Desember 2021

EXPLORE : ISSN: 2087-2062, Online ISSN: 2686-181X / DOI: http://dx.doi.org/10.36448/jsit.v12i2.2361

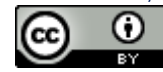

This work is licensed under a Creative Commons Attribution 4.0 International License 


\begin{tabular}{lll}
\hline APO012 - Mengelola resiko & 4,15 & Manage and Measurable \\
\hline APO013 - Mengelola keamanan & 3,50 & Manage and Measurable \\
\hline $\begin{array}{l}\text { MEA01 - Memantau, Mengevaluasi, dan Menilai Kinerja } \\
\text { dan Kesesuaian }\end{array}$ & 3,82 & Manage and Measurable \\
\hline
\end{tabular}

Berdasarkan table 4 di atas terdapat kesenjangan antar Kesenjangan tersebut dapat dijabarkan dalam table 5 di tingkat kematangan pada masing-masing komponen. bawah ini:

Tabel 5 Perbandingan tingkat kematangan

\begin{tabular}{cccc}
\hline \multirow{2}{*}{ Domain } & \multicolumn{2}{c}{ Tingkat Kematangan (Maturity level) } \\
\cline { 2 - 4 } & Saat ini & Ekspektasi & Kesenjangan \\
\hline EDM03 & 4,45 & 5 & $5-4,45=0,55$ \\
\hline EDM04 & 3,91 & 5 & $5-3,91=1,09$ \\
\hline APO02 & 3,65 & 5 & $5-3,65=1,35$ \\
\hline APO04 & 3,65 & 5 & $5-3,65=1,35$ \\
\hline APO07 & 4,12 & 5 & $5-4,12=0,88$ \\
\hline APO011 & 4,10 & 5 & $5-4,10=0,90$ \\
\hline APO012 & 4,15 & 5 & $5-4,15=0,85$ \\
\hline APO013 & 3,50 & 5 & $5-3,50=0,50$ \\
\hline MEA01 & 3,82 & 5 & $5-3,82=1,18$ \\
\hline$\Sigma$ & $\mathbf{3 , 9 2}$ & - & - \\
\hline
\end{tabular}

Berdasarkan hasil Analisa GAB dapat disimpulkan bahwa kematangan dari masing-masing entitas merupakan keterkaitan yang memiliki nilai pada rentan $0-1,5$ berdasarkan staka elspektasi. Secara grafik perkembangan rebtabab dalam setiap akuisisi dapat dituangan pada gambar 2 dalam bentuk grafik di bawah ini.

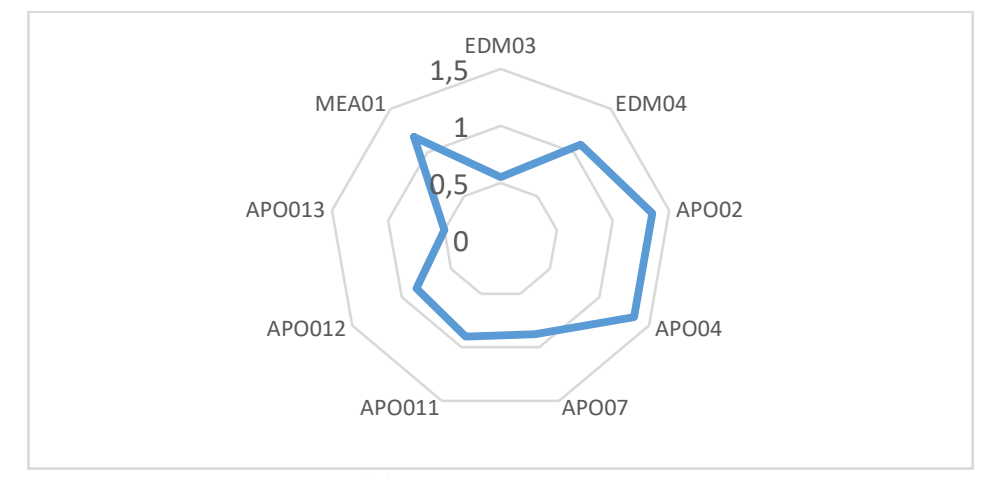

Gambar 2. Domain GAB Tingkat Kematangan (Maturity Level)

\section{Kesimpulan}

a. Proses pengukuran keakuratan pengolahan data pada Dinas Pendidikan Kabupaten Tulang Bawang Lampung telah dilakukan dengan menggunakan ACL (Audit Command Language) yang merupakan satuan dalam software GAS (Generalized Audit Software).

b. Dinas Pendidikan Kabupaten Tulang Bawang telah melakukan mitigasi terahadap tingkat kematangan pada skala 3,92 dengan level Manage and Measurable.

c. Proses penganalisaan sistem keakuratan data menggunakan kerangka kerja COBIT 5 yang terfokus pada enterprise goal organisasi setelah dilakukan penentuannya akan terlihat nilai kebutuhan IT related goals yang dapat dipergunakan sebagai pemilihan tahapan domain dalam prioses audit pada Dinas Pendidikan kabupaten Tulang Bawang. Berdasarkan masing-masing sub sistem diberlakukan pemetaan berdasarkan indicator kepentingan dalam koefisien objek dimana telah didapatkan hasil berdasarkan tingkat maturity yang pada sebagian besar sub sistem berada pada konsisi Manage and Measurable dalam skala indeks kematangan 3,5-4,49. 


\section{Daftar Pustaka}

[1] Ana Cláudia Amorim, Miguel Mira da Silvaa, Rúben Pereirab, Margarida Gonçalvesc, "Using agile methodologies for adopting COBIT", Elsevier, 101496, Volume 101, November 2021.

[2] Fathoni, Novita Simbolon and Dinna Yunika Hardiyanti, "Security Audit on Loan Debit Network Corporation System Using Cobit 5 and ISO 27001: 2013", Journal of Physics: Conference Series, 2019

[3] F Muttaqin, M Idhom, F A Akbar, M H P Swari, E D Putri, "Measurement of the IT Helpdesk Capability Level Using the COBIT 5 Framework", IOP Publishing Ltd, Journal of Physics: Conference Series, 2020

[4] George Morris William Tangka; Andrew Tanny Liem; Joe Yuan Mambu, "Information Technology Governance Audit Using the COBIT 5 Framework at XYZ University“, IEEE, 2nd International Conference on Cybernetics and Intelligent System (ICORIS), January 2021.

[5] Hasnaa Berrada, Jaouad Boutahar, Souhail El Ghazi El Houssaini, "Simplified IT Risk Management Maturity Audit System based on "COBIT 5 for Risk", (IJACSA) International Journal of Advanced Computer Science and Applications, Vol. 12, No. 8, 2021

[6] Haryani, T Misriati, R Hidayat, D Puspitasari, DA Muthia, I Elyana, "Information Technology Governance in Al Kautsar Islamic Elementary School Using COBIT 5 Framework", IOP Publishing Ltd, Journal of Physics: Conference Series, 2020

[7] I Riadi1, I T R Yanto, and E Handoyo, "Analysis of academic service cybersecurity in university based on framework COBIT 5 using CMMI", IOP Conference Series: Materials Science and Engineering, 2019

[8] Khairul Akram ZainolAriffina, Faris HanifAhmadb, "Indicators for maturity and readiness for digital forensic investigation in era of industrial revolution 4.0, Vol.105, Juni 2021, Elsevier Ltd. All rights reserved.

[9] Lanto Ningrayati Amali, Muhammad Rifai Katili, Sitti Suhada, Lillyan Hadjaratie, "The measurement of maturity level of information technology service based on COBIT 5 framework", Telkomnika, Vol 18, No 1,2020

[10] M R Katili, V Pateda, M G Djafri, L N Amali, "Measuring the capability level of IT governance: a research study of COBIT 5 at Universitas Negeri Gorontalo", Journal of Physics: Conference Series, IOP Publishing Ltd, International Conference on Education, Science and Technology 2019.

[11] Noorhasanah Zainuddin, Wing Wahyu Winarno, Nurfitria Ningsi, Yuwanda Purnamasari Pasrun, Muliyadi Muliyadi, "IT governance evaluation at the population and civil registry office in Kolaka district using COBIT 5 framework", Register, Jurnal Ilmiah Teknologi Sistem Informasi (Scientific Journal of Information System Technology), Vol 6 (2) pp. 86-95, 2020

[12] Qayssar Ali Al-Fatlawi, Dawood Salman Al Farttoosi, Akeel Hamza Almagtome, "Accounting Information Security and IT Governance Under COBIT 5 Framework: A Case Study", Webology, Volume 18, Special Issue on Information Retrieval and Web Search April, 2021.

[13] Rahmat Awaludin Rizal; Riyanarto Sarno; Kelly Rossa Sungkono, "COBIT 5 for Analysing Information Technology Governance Maturity Level on Masterplan E-Government", IEEE, iSemantic, 26 October 2020

[14] Ridha Hanafi; Lili Adi Wibowo; Agus Rahayu, "Organization and IT Strategic Alignment, Determination of IT Process Priorities using COBIT 5", International Conference on Advancement in Data Science, E-learning and Information Systems (ICADEIS), 11 December 2020.

[15] Sari Agustin Wulandari Anggi Permata Dewi M. Rizki Pohan Dana Indra Sensuse M.Mishbah Syamsudin, "Risk Assessment and Recommendation Strategy Based on COBIT 5 for Risk: Case Study SIKN JIKN Helpdesk Service"; Procedia Computer Science, Elsevier, Volume 161, Pages 168-177, 2019

[16] Syifaul Fuada, "Incident Management of Information Technology in the Indonesia Higher Education based on COBIT Framework: A Review, EAI Endorsed Transactions, Volume 6, Issue 21, 012019 - 03 2019, n 28 January 2019

[17] Yolanda Tatiana Sebastiáo Carolino, Sérgio Rodrigues Nunes, "The Maturity and Efficiency of IT Governance Processes Based on Cobit 5: A Case of a Health Sector Organization in Portugal", IEEE, 14th Iberian Conference on Information Systems and Technologies (CISTI), Juli 2019. 